\title{
Enhanced Antiviral Ability by a Combination of Zidovudine and Short Hairpin RNA Targeting Avian Leukosis Virus
}

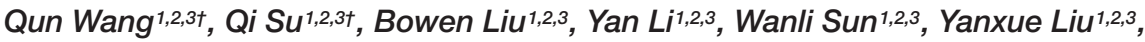 \\ Ruyu Xue 1,2,3, Shuang Chang ${ }^{1,2,3}$, Yixin Wang ${ }^{1,2,3}$ and Peng Zhao ${ }^{1,2,3 \star}$ \\ ${ }^{1}$ College of Animal Science and Veterinary Medicine, Shandong Agricultural University, Tai'an, China, ${ }^{2}$ Shandong Provincial \\ Key Laboratory of Animal Biotechnology and Disease Control and Prevention, Tai'an, China, ${ }^{3}$ Shandong Provincial \\ Engineering Technology Research Center of Animal Disease Control and Prevention, Tai'an, China
}

\section{OPEN ACCESS}

Edited by: Nejat Duzgunes,

University of the Pacific, United States

Reviewed by:

Xiaole Qi,

Harbin Veterinary Research Institute,

Chinese Academy of Agricultural

Sciences (CAAS), China

Qing Pan,

Harbin Veterinary Research Institute,

Chinese Academy of Agricultural

Sciences (CAAS), China

*Correspondence:

Peng Zhao

zhaopeng@sdau.edu.cn

${ }^{\dagger}$ These authors have contributed equally to this work

\section{Specialty section:}

This article was submitted to

Virology,

a section of the journa

Frontiers in Microbiology

Received: 04 November 2021 Accepted: 30 December 2021

Published: 16 February 2022

Citation:

Wang Q, Su Q, Liu B, Li Y, Sun W, Liu Y, Xue R, Chang S, Wang Y and

Zhao P (2022) Enhanced Antiviral Ability by a Combination of Zidovudine and Short Hairpin RNA

Targeting Avian Leukosis Virus.

Front. Microbiol. 12:808982.

doi: 10.3389/fmicb.2021.808982
Avian leukosis virus (ALV) causes tumor diseases in poultry and is circulating all over the world, leading to significant economic losses. In addition, mixed infection of ALV with other viruses is very common and is often reported to contaminate live vaccines. At present, there is no effective method to suppress the replication of ALV in vitro, so it is very difficult to remove it in mixed infection. As a retrovirus, the replication of ALV can be limited by reverse transcriptase (RT) inhibitors like zidovudine (AZT), but it also causes nontargeted cytotoxicity. To find the optimal solution in cytotoxicity and inhibition efficiency in vitro culture system, we firstly designed a combination therapy of AZT and short hairpin RNA (shRNA) targeting ALV and then verified its efficiency by multiple biological methods. Results showed that shRNA can effectively inhibit the expression of RT and then limit the replication of ALV. The combination of AZT and shRNA can significantly improve the antiviral efficiency in viral replication, shedding, and provirus assembly under the condition of low cytotoxicity. Overall, in this study, the combination therapy of AZT and shRNA targeting ALV showed excellent antiviral performance against ALV in vitro culture system. This method can be applied to multiple scenarios, such as the removal of ALV in mixed infection or the purification of contaminated vaccine strains.

Keywords: avian leukosis virus, reverse transcriptase, zidovudine, RNAi, shRNA

\section{INTRODUCTION}

Avian leukosis (AL) is an important oncogenic disease caused by avian leukosis virus (ALV; Payne and Nair, 2012). As an immunosuppressive virus, ALV is also easy to cause immune failure and secondary infection, resulting in huge economic losses (Su et al., 2019; Wang et al., 2020b). ALVs can be divided into 11 subgroups (designated A to K; Payne et al., 1992; Wang et al., 2012). Among them, ALV subgroup J (ALV-J) is the most pathogenic and epidemic subgroup, which is also highly prevalent in China (Gao et al., 2012; Lin et al., 2016; Su et al., 2018b; Zhou et al., 2019; Wang et al., 2020a). In addition, the long-term epidemic has also bred many recombinant or mutant strains and caused extensive mixed infection with other viruses (Cai et al., 2013; Su et al., 2018a, 2020; Liang et al., 2019; Zhang et al., 2020). Recently, a lot of studies reported the ALV contamination in 
live vaccines and even the seed viruses (Mao et al., 2020). However, there is no effective method to suppress the replication of ALV in vitro, so it is very difficult to remove it in mixed infection.

Avian leukosis virus belongs to alpha retrovirus and has a positive-strand RNA genome (Nair and Fadly, 2013). The genomic structure of ALV is highly similar to that of the human immunodeficiency virus (HIV), whereas both of them rely on reverse transcriptase (RT) for genome replication (Hurwitz and Leis, 1972; Battula and Loeb, 1976; Nasioulas et al., 1995; Coffin and Fan, 2016). RT inhibitors like lamivudine (LAM) and zidovudine (AZT) were designed to inhibit the replication efficiency of retroviruses, and many of them have been proved to be effective in several viruses, especially the HIV (DurandGasselin et al., 2008; Akanbi et al., 2012; Clark and Hu, 2015; Berruti et al., 2021). However, the wide application of RT inhibitors has also led to the emergence of many drug-resistant virus strains, which may even cause a more serious epidemic (Fanning et al., 2003; Kantor et al., 2004; Bulteel et al., 2014; Mulato et al., 2021).

RNA interference (RNAi) is a process of silencing gene expression in a specific way mediated by miRNA or short hairpin RNA (shRNA), which gradually become a promising therapeutic approach for treating viral diseases (van Rij and Andino, 2006; DeVincenzo, 2008; Wang et al., 2017; Berkhout, 2018). RNAi targeting retrovirus mRNA has been verified to effectively inhibit the replication of human and animal retroviruses such as HIV (Bennasser et al., 2007; Scarborough and Gatignol, 2017), hepatitis B virus (Chen et al., 2003; Hamasaki et al., 2003), feline leukemia virus (Lehmann et al., 2015), and simian immunodeficiency virus (Lim et al., 2008).

Our previous work has confirmed that RT inhibitors also work efficiently in ALV and can be used to eradicate the contamination of ALV and other retroviruses in vaccine virus seeds (Wang et al., 2015; Cui et al., 2019). However, it is notable that, with the increase of drug concentration, the cytotoxicity is also increasing, which limits the further application of AZT. In the present study, we combined RNAi and RT inhibitors to achieve higher inhibition of virus replication with low cytotoxicity, and we aimed to establish an effective method to remove ALV in mixed infection or contaminated vaccine seed viruses in vitro culture system.

\section{MATERIALS AND METHODS}

\section{Cells, Virus, and Drugs}

Avian leukosis virus subgroup J strain SDAU1005 (GenBank, access no. KT156668) was isolated from crossbreed broilers with fibrosarcoma, and the infectious clone and rescued virus of SDAU1005 was constructed and preserved in our laboratory (Wang et al., 2016). DF-1 cells were purchased from ATCC (United States) and cultured in Dulbecco's Modified Eagle Medium (DMEM; Gibco, United States) containing 10\% FBS, penicillin $(100 \mathrm{U} / \mathrm{ml})$, and streptomycin $(100 \mu \mathrm{g} / \mathrm{ml})$ at $37^{\circ} \mathrm{C}$ in a humidified atmosphere containing 5\% $\mathrm{CO}_{2}$. AZT (SigmaAldrich, United States) was dissolved in dimethylsulfoxide
(DMSO; SolarBio, Beijing, China) at $10 \mathrm{mg} / \mathrm{ml}$ and stored at $-80^{\circ} \mathrm{C}$. AZT was diluted with Dulbecco's PhosphateBuffered Saline (D-PBS) before use to ensure that the DMSO concentration was less than $0.5 \%(\mathrm{v} / \mathrm{v})$.

\section{CCK-8 Assay to Determine Cell Viability at Various Zidovudine Concentrations}

In 96-well microplates (Corning, United States), DF-1 cells were inoculated at a seeding density of $5 \times 10^{3}$ cells per well in $100 \mu \mathrm{l}$ of DMEM. Then, DF-1 cells were cultured with different concentrations of $\operatorname{AZT}(0,0.1,0.5,1,2,5$, and $10 \mu \mathrm{g} / \mathrm{ml})$ for $48 \mathrm{~h}$. The cytotoxicity of various concentrations of AZT was assayed by a CCK-8 Kit (NCM Biotech, Suzhou, China) following the manufacturer's specifications. Briefly, after 48 h of incubation, the supernatant was removed and cells were washed three times with D-PBS and cultured with an equal volume of fresh medium. Then, $10 \mu \mathrm{l}$ of CCK- 8 solution was immediately added to each well and samples were cultured in a $5 \% \mathrm{CO}_{2}$ incubator for $4 \mathrm{~h}$. The absorbance value of $450 \mathrm{~nm}$ was detected by a microplate reader (Thermo Fisher Scientific, United States), and the cell viability $(\mathrm{CV})$ was calculated according to Equation 1.

$$
C V=\frac{A(\text { Drug })-A(\text { Blank })}{A(\text { Control })-A(\text { Blank })} \times 100 \%
$$

\section{Dose-Response Curve to Analyze the Antiviral Effect of Zidovudine on Avian Leukosis Virus Subgroup J}

Zidovudine treatment was carried out in 96-well microplates. DF1 cells $(5,000$ cells per well) were infected with SDAU1005 stock $\left(50 \mathrm{TCID}_{50}\right)$ in microplates prefilled with $100 \mu \mathrm{l}$ of AZT with different concentrations (threefold serial dilutions). A column of DF-1 cells contains no drugs as positive control and a column of DF-1 cells contains no cells as blank control. The supernatant was harvested after the cells were cultured for an additional 5 days, and then, the ALV-p27 antigen was detected by an Avian Leukosis Virus Antigen Test Kit (IDEXX, United States) following the manufacturer's specifications. The absorbance value of $650 \mathrm{~nm}$ was detected by a microplate reader, and the S/P value (samples OD value - negative control value)/(positive control value - negative control value) was calculated according to the formula in instructions. The inhibition rate of virus (IV) was calculated according to Equation 2 and represents the proportion of virus titer reduction under drugs.

$$
I V=\left(1-\frac{S / P(\text { Drug })-S / P(\text { Blank })}{S / P(\text { Control })-S / P(B \text { lank })}\right) \times 100 \%
$$

The AZT concentration required to inhibit SDAU1005 replication by $50 \%\left(\mathrm{IC}_{50}\right)$ was generated by fitting the inhibition curves with four parameters nonlinear regression model.

\section{Construction of Short Hairpin RNA Expression Plasmids}

On the basis of the RT gene sequence of the ALV SDAU1005 strain, shRNAs were designed by BLOCK-iT RNAi Designer 
(Invitrogen, United States ${ }^{1}$ ). Two shRNAs were designed and synthesized in the RT active domain (RT-Rtv) and ribonuclease $\mathrm{H}$ active domain (RNase $\mathrm{H}$ ), respectively (Figure 1A). The sequences of shRNAs were subjected to BLASTN ${ }^{2}$ to verify their specificity. In addition, a nonspecific shRNA was designed to serve as a negative control shRNA that did not target the known avian genome and the known avian leukemia virus genome.

The complementary oligonucleotide sequences (Table 1) of shRNA, including sense sequence, a hairpin loop structure, antisense sequence, termination signal, and BamH I and Hind III restriction endonuclease site (Figure 1B), were synthesized by Takara (Beijing, China). The annealed shRNA duplexes were cloned into the linearized shRNA expression vector pBAsi-hU6 (Figure 1C). The recombinant shRNA expression plasmids were extracted by an E.Z.N.A. EndoFree Plasmid DNA Maxi Kit (Omega, United States) following the manufacturer's specifications and confirmed by PCR and sequence analysis (Sangon Biotech, Shanghai, China). Positive plasmids with the correct sequencing results were named sh-1-1, sh-1-2, sh-2-1, sh-2-2, and sh-NC, respectively. In addition, when the recombinant shRNA expression plasmids were transfected into DF-1 cells, they were transcribed into shRNA (Figure 1D).

\section{Construction of Reverse Transcriptase-EGFP Reporter Plasmid}

The sequence of RT gene was amplified from the infectious clone of ALV strain SDAU1005, and the EcoR I and Sal I restriction endonuclease sites were linked to both ends, respectively, of the RT gene using PCR amplification. The following pair of primers was used: EcoR-RT-F: 5' GAATTCTATGACTGTTGCGCTACATCTGGCTAT-3' and SalRT-R: 5'-GTCGACTTAATACGCTTGAAAGGTGGCTTGG-3' for the amplification of RT gene of ALV-J. Then, the PCR products were purified using a Gel Extraction Kit (Omega, United States) and subcloned into a pMD18-T vector (Takara, Beijing, China). The recombinant plasmids (pMD-RT) were extracted using a Plasmid DNA Mini Kit (Omega, United States). As a next step, to construct the EGFP reporter plasmid, pMD-RT plasmid was digested with EcoR I and Sal I and cloned into the linearized pEGFP-C1 vector. The endotoxinfree plasmid (RT-EGFP) was extracted and confirmed using the above method.

\section{Co-transfection of Reverse Transcriptase-EGFP Reporter Plasmid and Short Hairpin RNA Expression Plasmids}

For RT-EGFP reporter plasmid and shRNA expression plasmids co-transfection, DF-1 cells were inoculated in 12-well plates (Corning, United States) at a seeding density of $2 \times 10^{5}$ cells per well and continued to culture in a $\mathrm{CO}_{2}$ incubator until the cells reached approximately $80 \%$ confluence. After

${ }^{1}$ https://rnaidesigner.thermofisher.com

${ }^{2}$ http://blast.ncbi.nlm.nih.gov/Blast.cgi that, $1.6 \mu \mathrm{g}$ each of the shRNA expression plasmids (sh1-1, sh-1-2, sh-2-1, sh-2-2, and sh-NC) was co-transfected with $1.6 \mu \mathrm{g}$ RT-EGFP reporter plasmid to DF-1 cells using Lipofectamine $^{\mathrm{TM}} 2000$ (Invitrogen, United States) following the manufacturer's specifications. Briefly, after $6 \mathrm{~h}$ of incubation with opti-MEM $^{\mathrm{TM}}$ I Reduced Serum Medium (Gibco, United States), the supernatant was removed and cells were washed three times with D-PBS and cultured with an equal volume of fresh DMEM containing $10 \%$ FBS.

\section{Analysis of Reverse Transcriptase-EGFP Fusion Protein and Reverse Transcriptase mRNA Expression in DF-1 Cells}

At $48 \mathrm{~h}$ after co-transfection, the supernatant was removed and DF-1 cells were washed thrice gently with D-PBS. DF1 cells were fixed using 4\% paraformaldehyde for $15 \mathrm{~min}$ and then incubated with 4,6-diamidino-2-phenylindole (DAPI; Sigma-Aldrich, United States) for $5 \mathrm{~min}$ before visualizing the expression of RT-EGFP fusion proteins using fluorescence microscopy (Nikon, $200 \times$ ). At the same time, other DF-1 cells were washed thrice gently with D-PBS, trypsinized, and resuspended in cold D-PBS, and then, the percentage of EGFP fusion protein-positive cells was determined by LSRFortessa flow cytometer (BD, United States).

At $48 \mathrm{~h}$ after co-transfection, another group was harvested. Real-time PCR was later used to analyze the effect of shRNA interference on RT gene expression. Briefly, total RNA was extracted by an E.Z.N.A. Total RNA Kit (OMEGA, United States) following the manufacturer's specifications, and then, RNA concentrations were quantified using a NanoDrop ND-1000 spectrophotometer (Thermo Fisher Scientific, United States). Reverse transcription and genomic DNA removal were performed using a PrimeScript RT reagent Kit with gDNA Eraser (Takara, Beijing, China), and about $1 \mu \mathrm{g}$ of total RNA was reverse-transcribed into cDNA. Real-time PCR were performed on a Light Cycler 96 (Roche, Switzerland) using TB Green Premix Ex Taq (Takara, Beijing, China) following the manufacturer's specifications, and two pairs of primers (RT-F/R and $A C T B-\mathrm{F} / \mathrm{R}$, Table 2) were used to amplify $2 \mu \mathrm{l}$ of cDNA template in $20-\mu \mathrm{l}$ reaction system. The real-time PCR thermal cycling conditions were $95^{\circ} \mathrm{C}$ for $5 \mathrm{~min}$, followed by 40 cycles of denaturation at $95^{\circ} \mathrm{C}$ for $5 \mathrm{~s}$ and annealing and extension at $60^{\circ} \mathrm{C}$ for $34 \mathrm{~s}$. The expression levels of the RT gene were normalized to the $\beta$-actin gene ( $A C T B$, housekeeping gene), and the analyses of RT $\mathrm{mRNA}$ relative expression in each sample were performed by the $2^{-\Delta \Delta C T}$ method.

\section{CCK-8 Assay to Determine the Cell Viability of Short Hairpin RNA Combined With Zidovudine}

In 96-well microplates, AZT ( $1 \mu \mathrm{g} / \mathrm{ml})$ was incubated with DF1 cells transfected with $0.16 \mu \mathrm{g}$ of different shRNA expression plasmids, respectively, and CV was detected and calculated as previously described. 
A

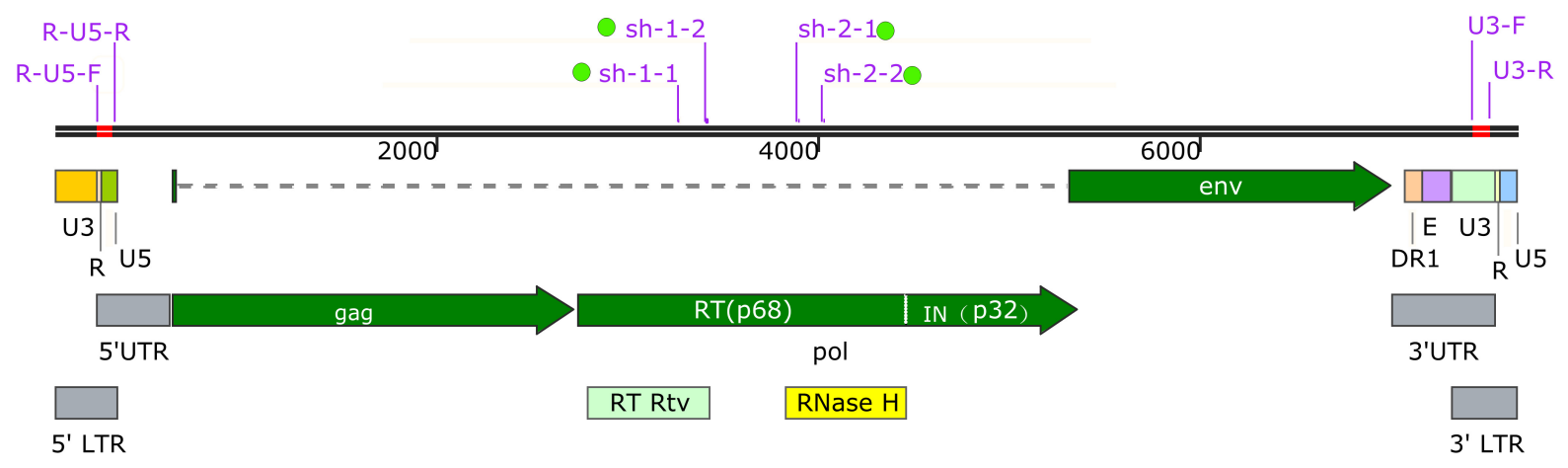

Avian leukosis virus SDAU1005 strain, complete genome (7652bp)

B

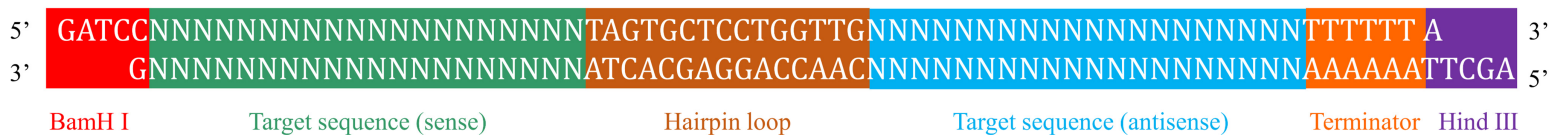

C

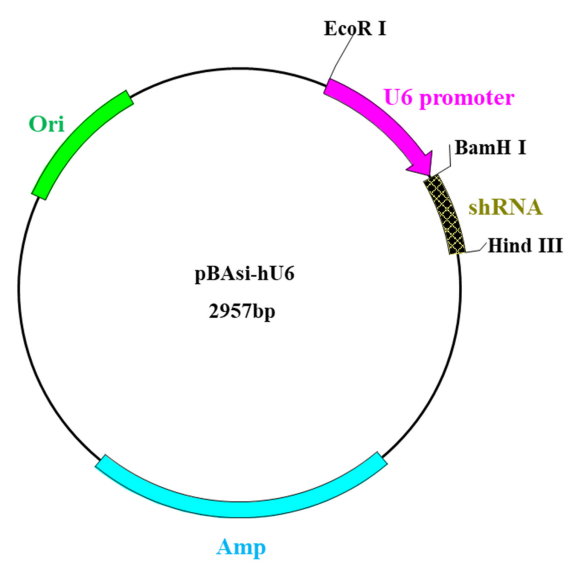

D

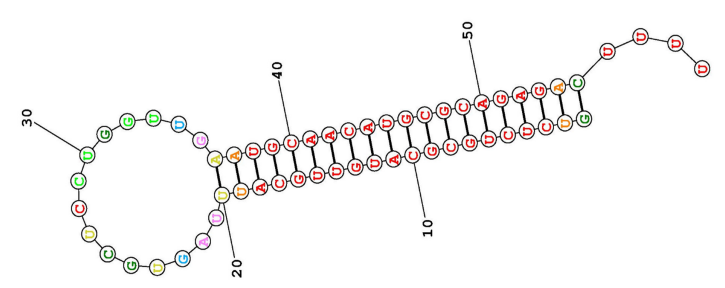

FIGURE 1 | Schematic description of target ALV genomic features, shRNA expression cassette and vector, and shRNA structure. (A) Genomic structure of ALV-J stain SDAU1005 and position of target shRNA: sh-1-1, sh-1-2, sh-2-1, and sh-2-2. (B) An inverted repeat is cloned into the shRNA expression vector. The inserted DNA is designed in the following order: BamH I restriction endonuclease site, sense sequence, hairpin loop structure, antisense sequence, termination signal, and Hind III restriction endonuclease site. The forward sequence and reserve sequence are both 67-nt long. (C) Map of the pBAsi-Hu6 shRNA expression vector. The inverted repeat is inserted into the corresponding site (BamH I/Hind III) of the vector. (D) The secondary structure of the shRNA predicted by RNA structure (http://rna.urmc.rochester.edu/RNAstructure.html).

\section{Virus Infection and Combination Therapy}

First, in 12-well plates, DF-1 cells were inoculated at a seeding density of $2 \times 10^{5}$ cells per well and continued to culture until the cells reached approximately $80 \%$ confluence. Then, the shRNA expression plasmids were transfected using Lipofectamine 2000 so that they were transcribed intracellularly and produced RNAi 
TABLE 1 | Synthetic shRNA oligonucleotide sequences.

\begin{tabular}{|c|c|c|}
\hline Name & & Sequences \\
\hline \multirow[t]{2}{*}{ sh-1-1 } & Top strand & 5'-GATCCGTCTCTGCGCATGTTGCATITAGTGCTCCTGGTTGAATGCAACATGCGCAGAGACTIITA-3' \\
\hline & Bottom strand & 5'-AGCTTAAAAAAGTCTCTGCGCATGTTGCATTCAACCAGGAGCACTAAATGCAACATGCGCAGAGACG-3' \\
\hline \multirow[t]{2}{*}{ sh-1-2 } & Top strand & 5'-GATCCGGCCCGGAGTACAATATCПTAGTGCTCCTGGTTGAAGATATTGTACTCCGGGCCTIITA-3' \\
\hline & Bottom strand & 5'-AGCTTAAAAAAGGCCCGGAGTACAATATCTTCAACCAGGAGCACTAAAGATATTGTACTCCGGGCCG-3' \\
\hline \multirow[t]{2}{*}{ sh-2-1 } & Top strand & 5'-GATCCGGCAAGGAGGTTGATATCCTTAGTGCTCCTGGTTGAGGATATCAACCTCCTTGCCTाITA-3' \\
\hline & Bottom strand & 5'-AGCTTAAAAAAGGCAAGGAGGTTGATATCCTCAACCAGGAGCACTAAGGATATCAACCTCCTTGCCG-3' \\
\hline \multirow[t]{2}{*}{ sh-2-2 } & Top strand & 5'-GATCCGGCGCGTCCACTGCATGTITAGTGCTCCTGGTTGAAACATGCAGTGGACGCGCCTIITA-3' \\
\hline & Bottom strand & 5'-AGCTTAAAAAAGGCGCGTCCACTGCATGTITCAACCAGGAGCACTAAAACATGCAGTGGACGCGCCG-3' \\
\hline \multirow[t]{2}{*}{ sh-NC } & Top strand & 5'-GATCCGTCTTAATCGCGTATAAGGCTAGTGCTCCTGGTTGGCCTTATACGCGATTAAGACTIIITA-3’ \\
\hline & Bottom strand & 5'-AGCTTAAAAAAGTCTTAATCGCGTATAAGGCCAACCAGGAGCACTAGCCTTATACGCGATTAAGACG-3' \\
\hline
\end{tabular}

effects. Next, $8 \mathrm{~h}$ after transfection, the supernatant was removed, and cells were washed three times with D-PBS and cultured with an equal volume of fresh medium containing AZT $(1 \mu \mathrm{g} / \mathrm{ml})$ so that both shRNA targeting RT gene and AZT play an antiviral role in DF-1 cells. ALV-J strain SDAU1005 stock (300 TCID 50 ), meanwhile, was inoculated into each well of 12-well plates. Culture supernatant and DF-1 cells were harvested at 24/48 h post-infection (hpi).

\section{Quantification of Viral RNA Loads}

Viral RNA loads in DF-1 cells were quantified by the real-time PCR method (primers ALV-F and ALV-R, Table 2) as previously described, and the levels of ALV RNA load were normalized to the $\beta$-actin gene (primers $A C T B-\mathrm{F}$ and $A C T B-\mathrm{R}$, Table 2). In addition, to determine the viral loads in cell culture supernatant at $48 \mathrm{hpi}$, an absolute quantitative real-time PCR of ALV-J was established. Put simply, the fragment amplified by primer ALVF/R was cloned into a pMD18-T vector to construct the standard plasmid pMD-ALV, and the plasmid was then determined using a spectrophotometer and diluted 10-fold series with Tris-EDTA buffer $(\mathrm{pH}=8.0)$ to construct a standard curve. Viral RNA was extracted by an E.Z.N.A. Total RNA Kit (OMEGA, United States) following the manufacturer's specifications, determined using a spectrophotometer, and reverse-transcribed into cDNA. ALVJ loads in the culture supernatant were detected by real-time

TABLE 2 | Real-time PCR primers used in this study.

\begin{tabular}{ll}
\hline Name & Sequences \\
\hline RT-F & 5'-CTAACGAGGCGAGGGAATG-3' \\
RT-R & 5'-TTGGTGGGTTGGGTGGAGA-3' \\
ALV-F & 5'-CAGAGAAGATACGGGTGGAAG-3' \\
ALV-R & 5'-CTATGACAAGCAATGCAAACAG-3' \\
ACTB-F & 5'-GAGAATTGTGCGTGACATCA-3' \\
ACTB-R & 5'-CCTGAACCTCTCATTGCCA-3' \\
R-U5-F & 5'-GCCATTTACCTCCCACCACA-3' \\
R-U5-R & 5'-GCAGGTGTTCGTAATCGTCAGG-3' \\
U3-F & 5'-GTCATGGTGTGATCGTGCC-3' \\
U3-R & 5'-TCTCTCTGCAACGCGGAAC-3' \\
HMG-14b-F & 5'-ACTGAAGAGACAAACCAAGAGC-3' \\
HMG-14b-R $R$ & 5'-CCAGCTGTTTAGACCAAAGAATAC-3'
\end{tabular}

PCR using cDNA templates, calculated according to the standard curve, and normalized to per $100 \mu \mathrm{l}$ of culture supernatant.

\section{Quantification of Pro-viral DNA Loads}

After DF-1 cells were harvested at 24 hpi, genomic DNA was then extracted using a DNeasy Blood \& Tissue Kit (Qiagen, United States) following the manufacturer's directions, followed by detection of the pro-viral DNA loads of ALV-J using real-time PCR. The primers used for real-time PCR are shown in Table 2. According to the previous methods (Julias et al., 2001), primers were designed to determine the ALV-J pro-viral DNA loads, in which primers R-U5-F/R were used to determine the synthesis of minus-strand strong stop DNA(-sssDNA) of ALV-J and primers $\mathrm{U} 3-\mathrm{F} / \mathrm{R}$ are used to amplify the ALV-J DNA specific for U3 to determine the amount of first-strand transfer. The pro-viral DNA loads (-sssDNA/U3DNA) of ALV-J were normalized to the HMG$14 b$ gene [single-copy gene in the chicken genome (Srikantha et al., 1990)], and the analyses of their expression levels in each sample were performed by the $2^{-\Delta \Delta \mathrm{CT}}$ method.

\section{Western Blot to Analyze the Expression of Viral Protein in DF-1 Cells}

DF-1 cells were harvested at 48 hpi and lysed on ice for 10 min using a cell lysis buffer (Beyotime Biotechnology, Shanghai, China) following the manufacturer's specifications. After centrifugation at $14,000 \times g$ for $5 \mathrm{~min}$ at $4^{\circ} \mathrm{C}$, the supernatant was collected and then assayed for total protein content using a BCA Protein Quantification Kit (TransGen Biotech, Beijing, China), and $20 \mu \mathrm{g}$ of total protein was subjected to $8 \%$ SDS-PAGE and transferred to a PVDF membrane (Millipore, United States). PVDF membranes were blocked using $5 \%$ skim milk for $1 \mathrm{~h}$ at room temperature, incubated with mouse anti-ENV mAb JE9 (Qin et al., 2001) or rabbit antiACTB antibody (Abcam, United Kingdom) at $4^{\circ} \mathrm{C}$ overnight, washed with Tris-Buffered Saline with Tween 20 (TBST) for three times, then incubated with HRP-conjugated goat antirabbit antibody (Abcam, UK) or goat anti-mouse antibody (Abcam, UK) at room temperature for $2 \mathrm{~h}$, and detected with SuperSignal West Pico PLUS chemiluminescence substrate after TBST cleaning for three times. Exposure development was performed using a chemiluminescence imaging system (Azure Biosystems, United States). 


\section{Indirect Immunofluorescence Assay to Analyze the Expression of Viral Protein in DF-1 Cells}

DF-1 cells were harvested at 48 hpi, washed thrice gently with D-PBS, fixed with $4 \%$ paraformaldehyde for 15 min, blocked with QuickBlock Blocking Buffer for Immunol Staining (Beyotime Biotechnology, Shanghai, China), incubated with mouse antiENV antibody (mAb JE9), washed thrice with PhosphateBuffered Saline with Tween 20 (PBST), incubated with FITCconjugated goat anti-mouse antibody (Abcam, United Kingdom), washed thrice with PBST again, and then incubated with DAPI for $5 \mathrm{~min}$ before visualizing the expression levels of viral protein in DF-1 cells using fluorescence microscopy (Nikon, 200×).

\section{ELISA to Analyze ALV-p27 Levels in the Supernatant of DF-1 Cells}

The supernatant of DF-1 cells was harvested at $48 \mathrm{hpi}$, and then, the ALV-p27 antigen was detected by a Leukosis Virus Antigen Test Kit (IDEXX Laboratories Inc., United States) following the manufacturer's specifications. The absorbance value of $650 \mathrm{~nm}$ was detected by a microplate reader, and the $\mathrm{S} / \mathrm{P}$ value was calculated according to the formula in instructions.

\section{Dose-Response Curve to Analyze Antiviral Effect of Short Hairpin RNA Combined With Zidovudine}

In 96-well microplates, DF-1 cells were transfected with $0.16 \mu \mathrm{g}$ of different shRNA expression plasmids, infected with SDAU1005 stock after $8 \mathrm{~h}$ of transfection, and treated with various concentrations of AZT, according to the methods mentioned above. Similarly, according to the methods mentioned above, the inhibition rates of virus in each group were detected and calculated, and the $\mathrm{IC}_{50}$ values were generated by fitting the inhibition curves. For the combination of AZT with different shRNA expression plasmids, the fold change of $\mathrm{IC}_{50}\left(\mathrm{FCIC}_{50}\right)$ was calculated with Equation 3.

$$
\mathrm{FCIC}_{50}=\frac{I C_{50}[\text { Mock shRNA }]}{I C_{50}[A L V-\text { targeted shRNA }]}
$$

\section{Statistical Analysis}

The results were expressed as the means \pm SDs, and statistical analysis was performed by one-way ANOVA in SPSS 25.0 (SPSS Inc., Chicago, IL, United States). According to Duncan's multiple-range test, $P<0.05$ was considered statistically significant.

\section{RESULTS}

\section{Effect of Different Concentrations of Zidovudine on Cell Viability}

High concentrations of drugs are usually accompanied by cytotoxicity. In this study, the effect of AZT at different concentration on $\mathrm{CV}$ was determined by the CCK- 8 assay. As shown in Figure 2A, AZT $(10 \mu \mathrm{g} / \mathrm{ml})$ induced a significant damage on DF-1 cells, but that of lower concentration is not significant. Briefly, CV was above $90 \%$ at $5 \mu \mathrm{g} / \mathrm{ml}$; moreover, when using a drug concentration of $1 \mu \mathrm{g} / \mathrm{ml}$, the CV was above $95 \%$, suggesting that AZT at this concentration caused less damage to DF-1 cells.

\section{Antiviral Effect of Zidovudine at Different Concentrations}

The inhibiting effect of AZT on ALV-J infection was further determined in this study, and the results were presented by a dose-response curve (Figure 2B). It was found that the antiviral effect is linear with the concentration from 0.01 to $10 \mu \mathrm{g} / \mathrm{ml}$. Moreover, the $\mathrm{IC}_{50}$ of ALV-J strain SDAU1005 was $0.379 \mu \mathrm{g} / \mathrm{ml}$. On the basis of the cytotoxicity of different concentrations of AZT determined in the previous section and the antiviral effect of different concentrations of AZT determined in this section, AZT at a concentration of $1 \mu \mathrm{g} / \mathrm{ml}$ (inhibit rate: $>70 \%$ ) was used in the next study to explore the effect of shRNA combined with AZT on ALV-J.

\section{Specific Short Hairpin RNAs Downregulated the Expression of Reverse Transcriptase in DF-1 Cells}

To evaluate whether shRNA can knockdown the expression of RT gene in DF-1 cells, RT-EGFP expression plasmid and four shRNA expression plasmids targeting the different regions of RT were co-transfected into DF-1 cells, whereas sh-NC expression plasmid served as control. At $48 \mathrm{~h}$ after co-transfection, EGFPrelated green fluorescence was observed using a fluorescence microscope. Compared with the negative control, four shRNAs all significantly knockdown the expression of RT-EGFP protein (Figure 3A). Further analysis of the co-transfected cells by flow cytometry revealed that the percentage of positive cells in each shRNA treatment group (sh-1-1, 16.5\%; sh-1-2, 16.1\%; sh-2-1, $20.3 \%$; sh-2-2, 16.3\%) was significantly decreased compared with the sh-NC group (33.9\%) (Figure 3B). After that, we determined the mRNA transcript levels of RT gene in different groups by real-time quantitative PCR and found that the relative expression levels of each shRNA group were all significantly decreased relative to the sh-NC group $(P<0.01$, Figure $3 \mathrm{C})$. Taking the above results together, we concluded that all four specific shRNA expression vectors constructed in present study could significantly silence the expression of the RT gene.

\section{The Combination of Zidovudine and Short Hairpin RNA Showed Low Cytotoxicity}

The previous works showed that AZT at a concentration of $1 \mu \mathrm{g} / \mathrm{ml}$ had less cytotoxicity $(\mathrm{CV}:>95 \%)$ and $>70 \%$ antiviral rate, and the designed shRNAs could effectively suppress the expression of the RT gene. Furthermore, we determined the cytotoxicity of the combination of shRNA and AZT using CCK-8 assay. As the results shown in Figure 4, cell viabilities were above 95\% when AZT and RNAi were used at the same time, indicating that this combination does not increase cytotoxicity. 

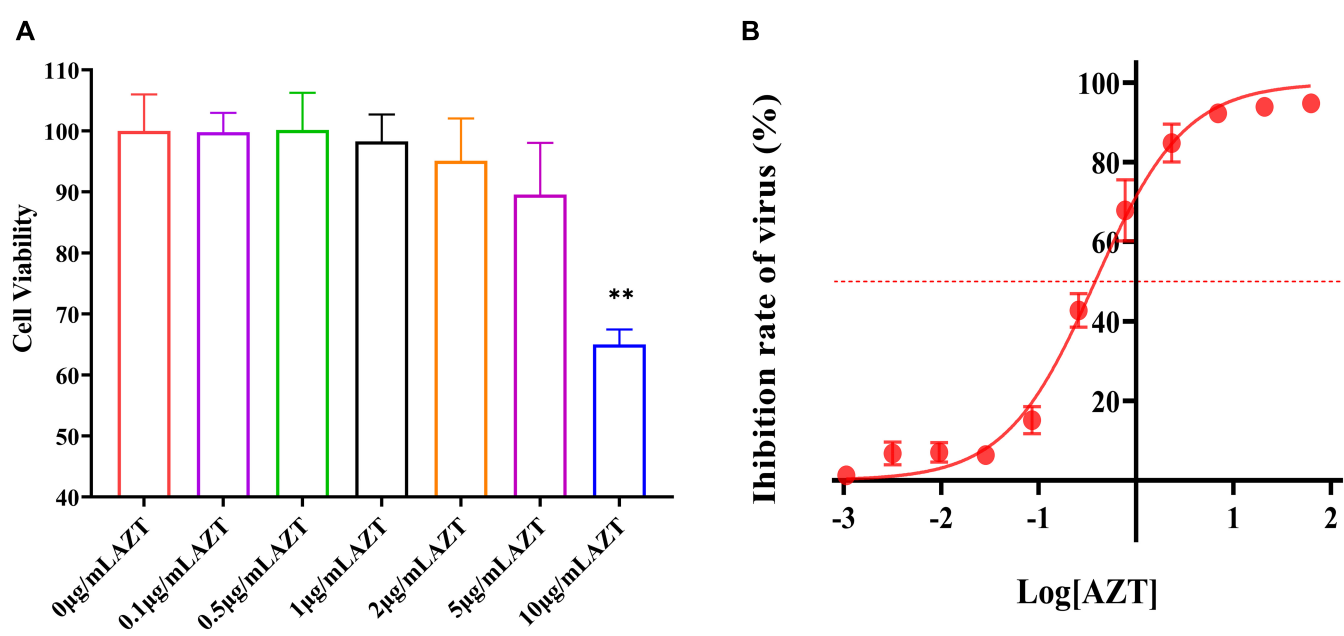

FIGURE 2 | Antiviral effect and cell viability of AZT at different concentrations. (A) Cell viability of DF-1 cells after AZT treatment at $0.1,0.5,1,2,5$, and $10 \mu \mathrm{g} / \mathrm{ml}$ for $48 \mathrm{~h}$ by CCK-8 assay. The experiment was repeated three times. The error bars represent the SD. ${ }^{* *} P<0.01$ and ns represents not statistically significant. (B) Dose-response curve of AZT reveals the dose relationship between AZT and ALV-J. The $x$-axis represents the log of the concentration of AZT ( $\mu \mathrm{g} / \mathrm{ml})$, and the $y$-axis represents the inhibition rate of virus (\%), which was calculated according to Equation 2 and represents the proportion of virus titer reduction under drugs. The red dotted line indicates the position of 50\% inhibition rate. The experiment was repeated eight times. The error bars represent the SD.

\section{The Combination of Zidovudine and Short Hairpin RNA Could Significantly Inhibit the Replication of Avian Leukosis Virus Subgroup $\mathrm{J}$ in DF-1 Cells}

We quantified the viral RNA loads in DF-1 cells of each group by real-time PCR to determine whether the combination of AZT and shRNA could significantly inhibit the replication of ALV-J in DF1 cells. The group treated with sh-NC expression plasmid without AZT served as control. The results showed that, compared with the control group (Figure 5A), the relative viral load of ALV-J genomic RNA was significantly reduced under the combination of AZT and RNAi. We further verified the above results by determining the expression levels of the envelope protein (ENV) of ALV-J by Western blot and IFA, which showed the consistent results (Figures 5B,C).

\section{The Combination of Zidovudine and Short Hairpin RNA Could Significantly Inhibit the Viral Shedding}

We collected cell supernatants from the different treatment groups at $48 \mathrm{hpi}$ and determined the copies of virions in the cell supernatants using real-time PCR (Figure 5D) and found that, compared with the negative control group $\left(10^{5.126 \pm 0.093}\right.$ copies $\left./ 100 \mu \mathrm{l}\right)$, using AZT $\left(10^{3.443} \pm 0.279\right.$ copies $\left./ 100 \mu \mathrm{l}\right)$ or shRNA expression plasmids $\left(10^{4.216} \pm 0.057\right.$ copies $/ 100 \mu \mathrm{l}, \quad 10^{4.313 \pm 0.051}$ copies/100 $\mu \mathrm{l}$, $10^{4.266 \pm 0.076}$ copies $/ 100 \mu \mathrm{l}$, and $10^{4.384 \pm 0.230}$ copies $/ 100 \mu \mathrm{l}$ ) alone could significantly suppress the viral copies in the DF-1 cell supernatants, but the combination of them was able to further decrease the ALV-J copies $\left(10^{2.830} \pm 0.095\right.$ copies $/ 100 \mu \mathrm{l}$, $10^{2.826 \pm 0.042}$ copies $/ 100 \mu \mathrm{l}, 10^{2.729} \pm 0.218$ copies $/ 100 \mu \mathrm{l}$, and $10^{2.917 \pm 0.079}$ copies $\left./ 100 \mu \mathrm{l}\right)$ in the supernatants.
To further confirm that shRNA in combination with AZT could synergistically suppress the release of ALV-J, the levels of ALV-p27 antigen in the supernatants at 48 hpi were determined by ELISA. The results (Figure 5E) showed that, compared with the negative control group, both shRNA and AZT alone suppressed the replication of ALV-J, and DF-1 cells co-treated with AZT and specific shRNA exhibited a better effect of inhibiting ALV-J release. The $\mathrm{S} / \mathrm{P}$ value of the co-treated groups (sh-1-1, $0.188 \pm 0.0164$; sh-1-2, $0.185 \pm 0.0319$; sh-2-1, $0.254 \pm 0.0435$; and sh-2-2, $0.224 \pm 0.0128$ ) were near the cut-off value of positive criteria of the p 27 antigen test kit. In conclusion, according to the levels of p27 antigen in the culture supernatants, shRNA expression plasmids targeting RT gene designed in this study and AZT had synergistic role of inhibit the release of ALV-J.

\section{The Combination of Zidovudine and Short Hairpin RNA Could Significantly Inhibit the Pro-viral Loads of Avian Leukosis Virus Subgroup J in DF-1 Cells}

In the process of ALV replication, the viral genomic RNA that enters the host cell is reverse-transcribed into a double-stranded DNA (pro-viral cDNA), and the formation of new ALV-J in the infected cell is the result of pro-viral DNA transcription and translation. Therefore, it is necessary to detect the pro-viral loads in DF-1 cells to explore the effect of combination therapy on the ALV-J pro-viral load in DF-1 cells. For this study, primers (location as shown in Figure 1A) were designed according to the method of Julias et al. (2001), and the HMG-14b gene was used as the housekeeping gene. The results showed that, compared with shRNAs targeting RNase $\mathrm{H}$ sequence (sh-2-1 and sh-2-2), shRNAs targeting RT-RTV sequence (sh-1-1 and sh-1-2) significantly reduced the -sssDNA load of ALV-J and further suppressed the synthesis of ALV-J minus strand DNA 
Wang et al.

Combination of $A Z T$ and RNA

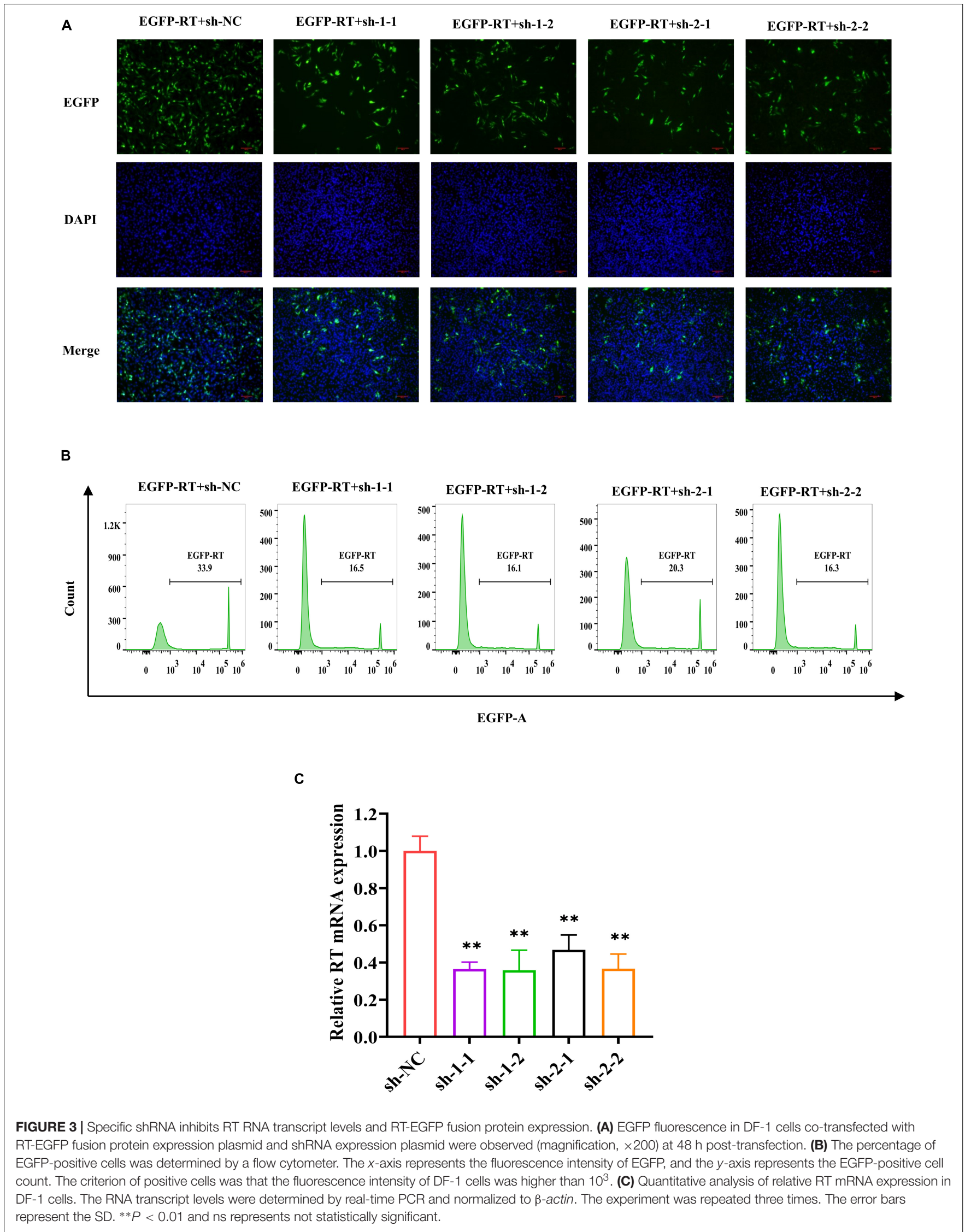

Frontiers in Microbiology | www.frontiersin.org

8

February 2022 | Volume 12 | Article 808982 


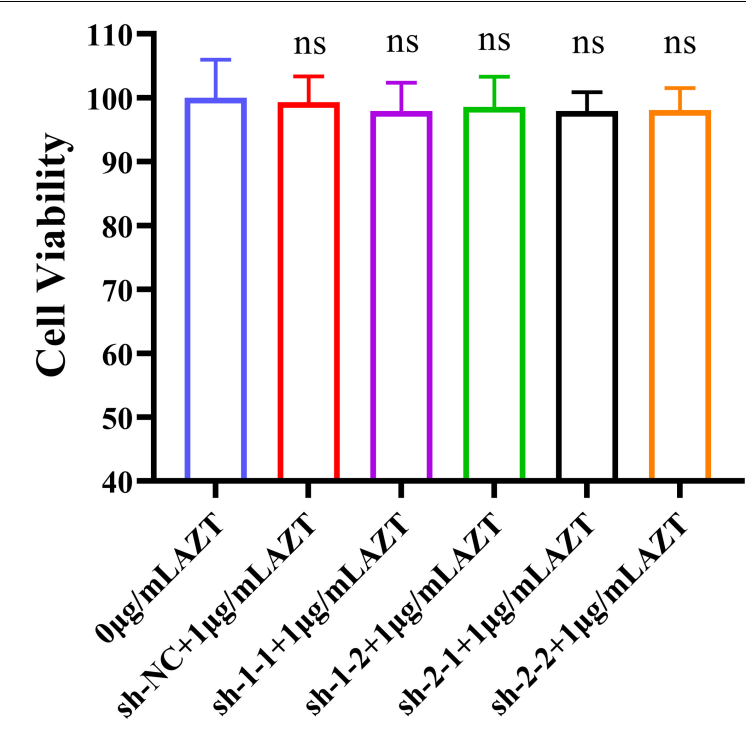

FIGURE 4 | Cell viability of DF-1 cells after the co-treatment with AZT at $1 \mu \mathrm{g} / \mathrm{ml}$ and shRNA expression plasmid for $48 \mathrm{~h}$ by CCK-8 assay. The experiment was repeated three times. The error bars represent the SD. ns represents not statistically significant.

when treated in combination with AZT (Figure 5F). However, the combination of shRNA targeting RNase $\mathrm{H}$ sequence (sh-2-1 or sh-2-2) and AZT has little effect on the synthesis of ALVJ minus strand DNA compared with AZT alone (Figure 5F). The relative U3 DNA loads of DF-1 cells treated with shRNA expression plasmids, AZT, or their combination were shown in Figure 5G, from which we found that both shRNAs targeting RT-RTV sequence and shRNAs targeting RNase $H$ sequence significantly reduce the U3DNA load of ALV-J and further suppress the transfer of ALV-J minus strand DNA when treated in combination with AZT.

\section{The Impact of Zidovudine in the Presence of Specific Short Hairpin RNA Pressure}

In previous studies, we found that the combination of shRNA and AZT might exhibit a synergistic or additive effects. To further confirm this, we explored the impact of AZT in the presence of shRNA pressure. Simply, supernatants were collected at 5 days post-infection, and the inhibitory activity of the antiviral drugs was calculated by comparing the p27 antigen levels of each group, after which dose-response curves were obtained and the $\mathrm{IC}_{50}$ values of ALV-J in different shRNA-transfected cells were generated by fitting the inhibition curves. The results were shown in Figure 6A, the inhibitory activity of drugs against viruses was changed under the combined effect of specific shRNA and AZT, and compared with the negative control group (sh-NC), dose-response curves for cells expressing specific shRNA (sh-11, sh-1-2, sh-2-1, or sh-2-2) shifted to the left, indicating that specific shRNAs can significantly increase the inhibitory activity of AZT on ALV-J. After that, we plotted the FCIC $_{50}$ values of
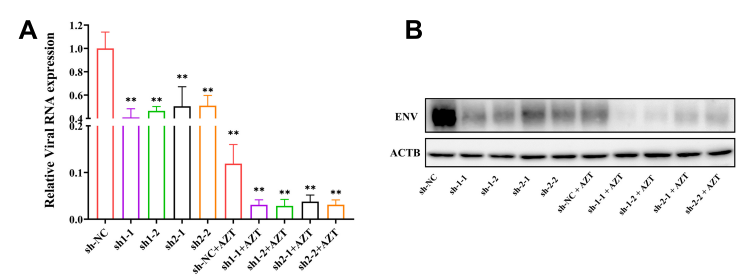

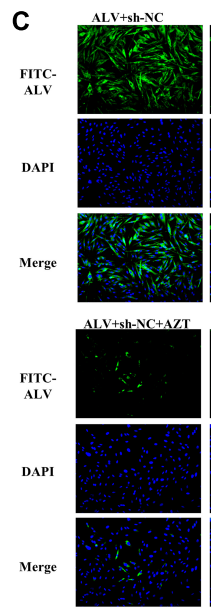

D

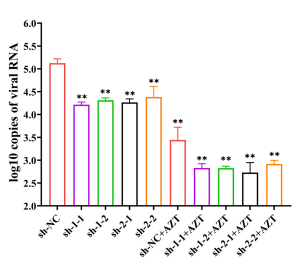

F

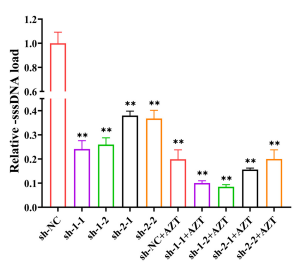

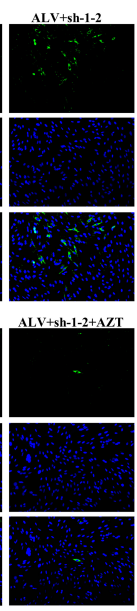

E
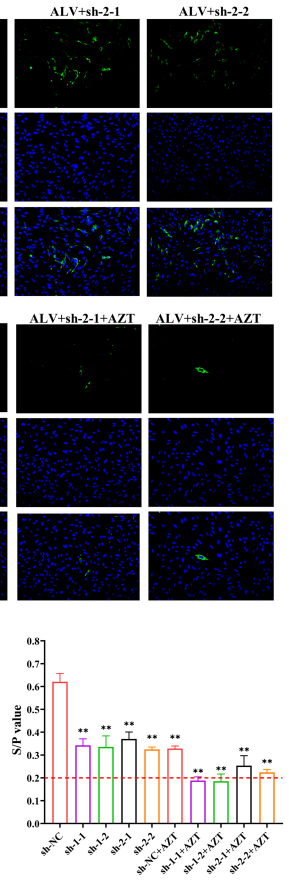

G

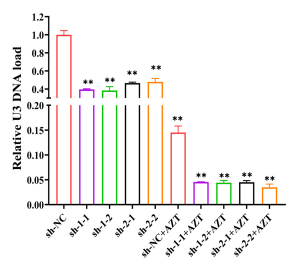

FIGURE 5 | Additive antiviral activity of shRNA and AZT. (A) Quantitative analysis of relative ALV RNA expression in DF-1 cells. The viral RNA levels were determined by real-time PCR and normalized to $\beta$-actin. (B) Western blot analysis of ALV-J ENV and $\beta$-actin in DF-1 cells. The expression levels of the envelope protein of ALV-J were normalized against $\beta$-actin.

(C) Immunofluorescence detection of ALV-J in DF-1 cells. The expression of envelope protein of ALV-J was observed under a fluorescence microscope (magnification, $\times 200$ ). Bright green indicates the presence of ALV-J-positive cell, and blue represents nuclei. (D) ALV-J loads in culture supernatant. The copies of ALV-J RNA were detected by real-time PCR and normalized to per $100 \mu \mathrm{l}$ of culture supernatant. (E) p27 antigen levels of ALV-J were detected by ELISA. The red dotted line indicates the cut-off value $(S / P=0.2)$ of the positive criteria. (F,G) Quantitative analysis of the synthesis or transfer of the minus strand DNA of ALV-J in DF-1 cells. The pro-viral DNA levels were determined by real-time PCR and normalized to HMG-14b. ${ }^{* *} P<0.01$ and ns represents not statistically significant. All experiments were repeated three times. The error bars represent the SD.

different specific shRNA transfection groups compared with shNC transfection group to further reveal the synergistic effect of shRNA and AZT in inhibiting ALV-J replication (Figure 6B), 
A

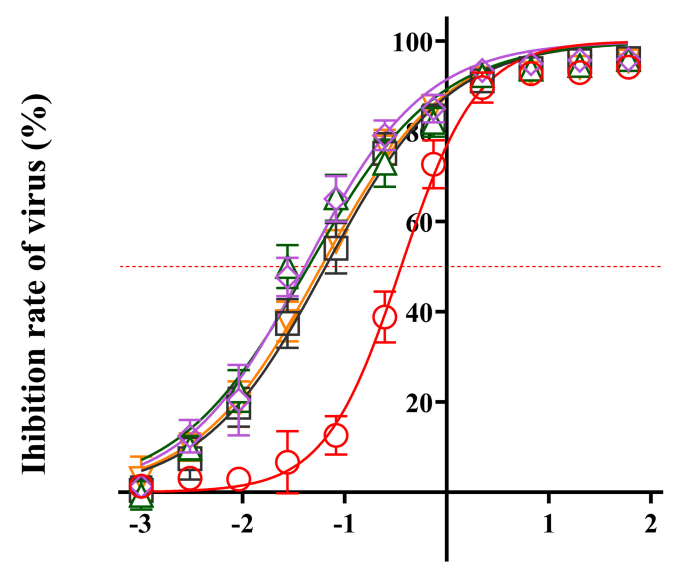

$\ominus$ sh-NC+SDAU1005

$\ominus$ sh-1-1+SDAU1005

$\triangle$ sh-1-2+SDAU1005

日 sh-2-1+SDAU1005
$\forall$ sh-2-2+SDAU1005
B

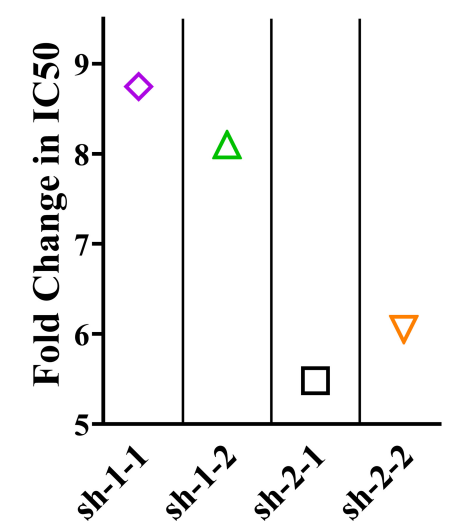

$\log [\mathrm{AZT}]$

FIGURE 6 | Antiviral activity of AZT was changed under the pressure of specific shRNA. (A) Dose-response curve of AZT in DF-1 cells expressing shRNAs. The $x$-axis represents the log of the concentration of AZT $(\mu \mathrm{g} / \mathrm{ml})$, and the $y$-axis represents the inhibition rate of virus (\%), which was calculated according to Equation 2 and represents the proportion of virus titer reduction under drugs. The red dotted line indicates the position of $50 \%$ inhibition rate, according to which we can observe the shift of $I C_{50}$. The experiment was repeated four times. The error bars represent the SD. (B) The fold change of $I C_{50}$. The IC $I_{50}$ values were generated by fitting the inhibition curves, and the $\mathrm{FClC}_{50}$ was calculated as Equation 3.

and the results showed that the combination of specific shRNA and AZT significantly increased the antiviral activity of AZT, and shRNAs targeting the RT-RTV sequence (sh-1-1 and sh-12) showed better synergistic activity than shRNAs targeting the RNase $\mathrm{H}$ sequence (sh-2-1 and sh-2-2).

\section{DISCUSSION}

Avian leukosis virus subgroup J infections have been reported worldwide and continue to pose a significant threat to the poultry industry (Landman et al., 2002; Fenton et al., 2005; Gao et al., 2010; Payne and Nair, 2012; Shittu et al., 2019). In addition, the mixed infection of ALV with other viruses or the contamination of it in live vaccines makes this disease more severe. However, up to now, there is no effective method to inhibit ALV virus replication in vitro; thus, it is difficult to decontaminate the vaccine seed virus or purify the wild strains with the co-infection of ALV.

Although AZT and other RT inhibitors have a good inhibitory effect on retroviruses, it cannot be ignored that they also cause significant damage to host cells especially at a high concentration. Another noteworthy problem is that the antiviral mutants may be selected under the pressure of AZT, which leads to drug resistance (Meng, 2018). The application of multi-antiviral methods with different mechanisms to inhibit virus replication, often refer to as combination therapy, has always been a promising therapeutic (Adamson and Freed, 2010). It cannot only effectively inhibit virus replication but avoid generating drug-resistant strains (Hashmat et al., 2020). Therefore, we hope to use combinatorial antiviral therapy to inhibit the replication of ALV-J in vitro culture system, and our first thought is the combination of RNAi (Chen et al., 2004; Kanda et al., 2007; Gao et al., 2008; Wang et al., 2017) and AZT.

At present, there are several reports on the application of RNAi to inhibit ALV (Chen et al., 2007; Meng et al., 2011; Wei et al., 2015). Similarly, in this study, shRNA expression plasmids were used to inhibit the replication of ALV-J. Both ALV and HIV are retroviruses with similar genomic structure. The pol gene of ALV encodes RT (P68) and integrase (In, P32). RT includes RNA-dependent DNA polymerase active domain and $\mathrm{RNase} \mathrm{H}$ active domain, which are necessary to complete viral reverse transcription (Herschhorn and Hizi, 2010; Justice and Beemon, 2013; Andrake and Skalka, 2015). Because RT is essential during ALV replication, shRNA expression plasmids targeting the key domains of ALV-J RT was designed at present study, and the successful application of shRNAs in inhibiting ALV-J RT gene expression in DF-1 cells was confirmed by co-transfection of shRNA expression plasmids and pEGFP-RT fusion protein expression plasmid.

After evaluating the cytotoxicity and antiviral activity of different concentrations of AZT in vitro culture system, we first determined that AZT at a concentration of $1 \mu \mathrm{g} / \mathrm{ml}$ was used in present study to explore the antiviral activity of the combination therapy, and then, we compared the antiviral effects of AZT and shRNA expression plasmids on ALV-J alone or in combination. We determined the relative expression of viral RNA and viral envelope protein in DF-1 cells and found that shRNA and AZT had a significant synergistic effect on inhibiting ALVJ replication in DF-1 cells. After that viral RNA copies and p27 antigen concentrations of ALV-J in culture supernatants were further detected by real-time PCR and ELISA. Similarly, the 
synergistic effect of the two was observed. We speculate that the reduction of ALV-J virions in the cell supernatant may be related to the inhibition of intracellular virus transcription or translation by AZT or shRNA, rather than both directly affecting virus release. In addition, we determined the synthesis and transfer of minus strand DNA during reverse transcription by detecting the relative expression of -sssDNA and U3 DNA of ALV-J, to explore the effect of the combination of shRNA and AZT on ALVJ provirus load in DF-1 cells. It should be noted that, compared with shRNAs targeting RNase $\mathrm{H}$ active domain (sh-2-1 and sh2-2), shRNAs targeting RT active domain (sh-1-1 and sh-1-2) significantly reduced the -sssDNA load of ALV-J and further suppressed the synthesis of ALV-J minus strand DNA when treated in combination with AZT (Figure 5F). We speculate that the reduction of ALV-J pro-viral loads may be due to the co-treatment of shRNA and AZT that further suppressed the RNA-dependent DNA polymerase activity of ALV-J and then affects the synthesis of viral negative strand DNA. After that, we further confirmed the synergistic effect of shRNA and AZT in inhibiting ALV-J replication by plotting the dose-response curve and calculating FCIC $_{50}$ (Figure 6). The results showed that the specific shRNAs significantly increased the antiviral activity of AZT on ALV-J, and shRNAs targeting RT active domain showed better synergistic effect than those targeting the RNase $\mathrm{H}$ active domain. Overall, shRNA and AZT had a good effect on the inhibition of ALV-J, but shRNA therapy alone was less effective than AZT alone, and it would cause a significant damage to host cells if we continue to carry on a high dose of AZT. In the case of the co-treatment of shRNA and AZT, the inhibition rate of ALV-J was improved without increasing cytotoxicity of AZT.

Finally, it must be emphasized that shRNA or AZT cannot completely kill the virus. Although the combination of shRNA and AZT may effectively avoid the generation of drug-resistant strains (Presloid and Novella, 2015), drug-resistant mutations or shRNA target sequence mutations are still noteworthy (Westerhout et al., 2005; Berkhout and Das, 2012). In addition, the application scenario of this method may be limited. Firstly, it can be used to remove ALV from some contaminated vaccine strains. The transmission of ALV caused by vaccine contamination is emerging all over the world, and there is no

\section{REFERENCES}

Adamson, C. S., and Freed, E. O. (2010). Novel approaches to inhibiting HIV-1 replication. Antiviral Res. 85, 119-141. doi: 10.1016/j.antiviral.2009.09.009

Akanbi, M. O., Scarsi, K. K., Taiwo, B., and Murphy, R. L. (2012). Combination nucleoside/nucleotide reverse transcriptase inhibitors for treatment of HIV infection. Expert Opin. Pharmacother. 13, 65-79. doi: 10.1517/14656566.2012. 642865

Andrake, M. D., and Skalka, A. M. (2015). Retroviral integrase: then and now. Annu. Rev. Virol. 2, 241-264. doi: 10.1146/annurev-virology-100114-055043

Battula, N., and Loeb, L. A. (1976). On the fidelity of DNA replication. Lack of exodeoxyribonuclease activity and error-correcting function in avian myeloblastosis virus DNA polymerase. J. Biol. Chem. 251, 982-986.

Bennasser, Y., Yeung, M. L., and Jeang, K. T. (2007). RNAi therapy for HIV infection: principles and practicalities. BioDrugs 21, 17-22. doi: 10.2165/ 00063030-200721010-00003

Berkhout, B. (2018). RNAi-mediated antiviral immunity in mammals. Curr. Opin. Virol. 32, 9-14. doi: 10.1016/j.coviro.2018.07.008 clear plan on how to effectively decontaminate the ALV in contaminated vaccine strains (Mao et al., 2020). Our antiviral strategy can continuously inhibit ALV in vitro passages, thus increasing the possibility of obtaining clean vaccine seed virus through plaque screening. In addition, this method can be used to purify some wild viral strains mixed with ALV, especially the coinfection of ALV and other virus is very common (Su et al., 2019).

\section{CONCLUSION}

In conclusion, shRNA in combination with AZT was able to significantly inhibit ALV-J replication in vitro culture system, which provides a reference basis for the development of effective method for suppressing the replication of ALV-J and other similar retroviruses.

\section{DATA AVAILABILITY STATEMENT}

The original contributions presented in the study are included in the article/supplementary material, further inquiries can be directed to the corresponding author.

\section{AUTHOR CONTRIBUTIONS}

QW and QS conceived and performed the experiments, analyzed the data, and drafted the manuscript. PZ supervised the project and revised the manuscript. YW, QW, BL, YL, YXL, RX, WS, and SC performed part of the experiments. All authors contributed to the article and approved the submitted version.

\section{FUNDING}

This work was supported by the grants from the National Natural Science Foundation of China (\#31402226) and the National Key Research and Development Program of China (2016YFD0501606).

Berkhout, B., and Das, A. T. (2012). HIV-1 escape from RNAi antivirals: yet another houdini action? Mol. Ther. Nucleic Acids 1:e26. doi: 10.1038/mtna.2012.22

Berruti, M., Riccardi, N., Canetti, D., Lo Caputo, S., Taramasso, L., and Di Biagio, A. (2021). Injectable antiretroviral drugs: back to the future. Viruses 13:228. doi: $10.3390 / \mathrm{v} 13020228$

Bulteel, N., Bansi-Matharu, L., Churchill, D., Dunn, D., Bibby, D., Hill, T., et al. (2014). The emergence of drug resistant HIV variants at virological failure of HAART combinations containing efavirenz, tenofovir and lamivudine or emtricitabine within the UK Collaborative HIV Cohort. J. Infect. 68, 77-84. doi: 10.1016/j.jinf.2013.09.005

Cai, L., Shen, Y., Wang, G., Guo, H., Liu, J., and Cheng, Z. (2013). Identification of two novel multiple recombinant avian leukosis viruses in two different lines of layer chicken. J. Gen. Virol. 94, 2278-2286. doi: 10.1099/vir.0.054239-0

Chen, M., Granger, A. J., Vanbrocklin, M. W., Payne, W. S., Hunt, H., Zhang, H., et al. (2007). Inhibition of avian leukosis virus replication by vector-based RNA interference. Virology 365, 464-472. doi: 10.1016/j.virol.2007.04.013

Chen, W., Yan, W., Du, Q., Fei, L., Liu, M., Ni, Z., et al. (2004). RNA interference targeting VP1 inhibits foot-and-mouth disease virus replication in BHK-21 cells 
and suckling mice. J. Virol. 78, 6900-6907. doi: 10.1128/jvi.78.13.6900-6907. 2004

Chen, Y., Du, D., Wu, J., Chan, C. P., Tan, Y., Kung, H. F., et al. (2003). Inhibition of hepatitis B virus replication by stably expressed shRNA. Biochem. Biophys. Res. Commun. 311, 398-404. doi: 10.1016/j.bbrc.2003.10.009

Clark, D. N., and Hu, J. (2015). Hepatitis B virus reverse transcriptase - Target of current antiviral therapy and future drug development. Antiviral Res. 123, 132-137. doi: 10.1016/j.antiviral.2015.09.011

Coffin, J. M., and Fan, H. (2016). The discovery of reverse transcriptase. Annu. Rev. Virol. 3, 29-51. doi: 10.1146/annurev-virology-110615-035556

Cui, S., Li, Y., Wang, Y., Cui, Z., Chang, S., and Zhao, P. (2019). Joint treatment with azidothymidine and antiserum for eradication of avian leukosis virus subgroup a contamination in vaccine virus seeds. Poult. Sci. 98, 629-633. doi: $10.3382 / \mathrm{ps} /$ pey257

DeVincenzo, J. P. (2008). RNA interference strategies as therapy for respiratory viral infections. Pediatr. Infect. Dis. J. 27, S118-S122. doi: 10.1097/INF. 0b013e318168b759

Durand-Gasselin, L., Pruvost, A., Dehée, A., Vaudre, G., Tabone, M. D., Grassi, J., et al. (2008). High levels of zidovudine (AZT) and its intracellular phosphate metabolites in AZT- and AZT-lamivudine-treated newborns of human immunodeficiency virus-infected mothers. Antimicrob. Agents Chemother. 52, 2555-2563. doi: 10.1128/aac.01130-07

Fanning, G., Amado, R., and Symonds, G. (2003). Gene therapy for HIV/AIDS: the potential for a new therapeutic regimen. J. Gene Med. 5, 645-653. doi: $10.1002 /$ jgm.436

Fenton, S. P., Reddy, M. R., and Bagust, T. J. (2005). Single and concurrent avian leukosis virus infections with avian leukosis virus-J and avian leukosis virusA in Australian meat-type chickens. Avian Pathol. 34, 48-54. doi: 10.1080/ 03079450400025356

Gao, Y. L., Qin, L. T., Pan, W., Wang, Y. Q., Le Qi, X., Gao, H. L., et al. (2010). Avian leukosis virus subgroup J in layer chickens, China. Emerg. Infect. Dis. 16, 1637-1638. doi: 10.3201/eid1610.100780

Gao, Y., Liu, W., Gao, H., Qi, X., Lin, H., Wang, X., et al. (2008). Effective inhibition of infectious bursal disease virus replication in vitro by DNA vector-based RNA interference. Antiviral Res. 79, 87-94. doi: 10.1016/j.antiviral.2007.11.007

Gao, Y., Yun, B., Qin, L., Pan, W., Qu, Y., Liu, Z., et al. (2012). Molecular epidemiology of avian leukosis virus subgroup J in layer flocks in China. J. Clin. Microbiol. 50, 953-960. doi: 10.1128/jcm.06179-11

Hamasaki, K., Nakao, K., Matsumoto, K., Ichikawa, T., Ishikawa, H., and Eguchi, K. (2003). Short interfering RNA-directed inhibition of hepatitis B virus replication. FEBS Lett. 543, 51-54. doi: 10.1016/s0014-5793(03)00 400-9

Hashmat, R., Yousaf, M. Z., Rahman, Z., Anjum, K. M., Yaqoob, A., and Imran, M. (2020). CRISPR-CAS replacing antiviral drugs against HIV: an update. Crit. Rev. Eukaryot. Gene Expr. 30, 77-83. doi: 10.1615/CritRevEukaryotGeneExpr. 2020028233

Herschhorn, A., and Hizi, A. (2010). Retroviral reverse transcriptases. Cell Mol. Life Sci. 67, 2717-2747. doi: 10.1007/s00018-010-0346-2

Hurwitz, J., and Leis, J. P. (1972). RNA-dependent DNA polymerase activity of RNA tumor viruses. I. Directing influence of DNA in the reaction. J. Virol. 9, 116-129. doi: 10.1128/jvi.9.1.116-129.1972

Julias, J. G., Ferris, A. L., Boyer, P. L., and Hughes, S. H. (2001). Replication of phenotypically mixed human immunodeficiency virus type 1 virions containing catalytically active and catalytically inactive reverse transcriptase. J. Virol. 75, 6537-6546. doi: 10.1128/jvi.75.14.6537-6546.2001

Justice, J. T., and Beemon, K. L. (2013). Avian retroviral replication. Curr. Opin. Virol. 3, 664-669. doi: 10.1016/j.coviro.2013.08.008

Kanda, T., Steele, R., Ray, R., and Ray, R. B. (2007). Small interfering RNA targeted to hepatitis $\mathrm{C}$ virus 5 ' nontranslated region exerts potent antiviral effect. J. Virol. 81, 669-676. doi: 10.1128/jvi.01496-06

Kantor, R., Shafer, R. W., Follansbee, S., Taylor, J., Shilane, D., Hurley, L., et al. (2004). Evolution of resistance to drugs in HIV-1-infected patients failing antiretroviral therapy. Aids 18, 1503-1511. doi: 10.1097/01.aids.0000131358. $29586.6 \mathrm{~b}$

Landman, W. J., Post, J., Boonstra-Blom, A. G., Buyse, J., Elbers, A. R., and Koch, G. (2002). Effect of an in ovo infection with a Dutch avian leukosis virus subgroup J isolate on the growth and immunological performance of SPF broiler chickens. Avian Pathol. 31, 59-72. doi: 10.1080/03079450120106633
Lehmann, M., Weber, K., Rauch, G., Hofmann-Lehmann, R., Hosie, M. J., Meli, M. L., et al. (2015). [Efficacy of siRNA on feline leukemia virus replication in vitro]. Berl. Munch. Tierarztl. Wochenschr. 128, 209-217.

Liang, X., Gu, Y., Chen, X., Li, T., Gao, Y., Wang, X., et al. (2019). Identification and characterization of a novel natural recombinant avian leucosis virus from Chinese indigenous chicken flock. Virus Genes 55, 726-733. doi: 10.1007/ s11262-019-01695-7

Lim, H. G., Suzuki, K., Cooper, D. A., and Kelleher, A. D. (2008). Promoter-targeted siRNAs induce gene silencing of simian immunodeficiency virus (SIV) infection in vitro. Mol. Ther. 16, 565-570. doi: 10.1038/sj.mt.6300380

Lin, W., Li, X., Dai, Z., Zhang, X., Chang, S., Zhao, P., et al. (2016). Molecular epidemiology of J-subgroup avian leukosis virus isolated from meat-type chickens in southern China between 2013 and 2014. Arch. Virol. 161, 30393046. doi: 10.1007/s00705-016-3003-8

Mao, Y., Su, Q., Li, J., Jiang, T., and Wang, Y. (2020). Avian leukosis virus contamination in live vaccines: a retrospective investigation in China. Vet. Microbiol. 246:108712. doi: 10.1016/j.vetmic.2020.108712

Meng, F. (2018). Genetic Diversity of Subgroup J Avian Leukosis Virus under the Selection in Different Tissues, Cells and Drugs. Ph.D. thesis. Taian: Shandong Agricultural University.

Meng, Q. W., Zhang, Z. P., Wang, W., Tian, J., and Xiao, Z. G. (2011). Enhanced inhibition of Avian leukosis virus subgroup J replication by multi-target miRNAs. Virol. J. 8:556. doi: 10.1186/1743-422x-8-556

Mulato, A., Acosta, R., Chang, S., Martin, R., Yant, S. R., Cihlar, T., et al. (2021). Simulating HIV breakthrough and resistance development during variable adherence to antiretroviral treatment. J. Acquir. Immune Defic. Syndr. 86, 369-377. doi: 10.1097/qai.0000000000002562

Nair, V., and Fadly, A. (2013). "Leukosis/sarcoma group," in Diseases of Poultry, 13th Edn, eds D. E. Swayne, J. R. Glisson, L. R. McDougald, L. K. Nolan, D. L. Suarez, and V. Nair (Ames, IA: Wiley-Blackwell), 553-592.

Nasioulas, G., Hughes, S. H., Felber, B. K., and Whitcomb, J. M. (1995). Production of avian leukosis virus particles in mammalian cells can be mediated by the interaction of the human immunodeficiency virus protein Rev and the Revresponsive element. Proc. Natl. Acad. Sci. U.S.A. 92, 11940-11944. doi: 10.1073/ pnas.92.25.11940

Payne, L. N., and Nair, V. (2012). The long view: 40 years of avian leukosis research. Avian Pathol. 41, 11-19. doi: 10.1080/03079457.2011.646237

Payne, L. N., Howes, K., Gillespie, A. M., and Smith, L. M. (1992). Host range of Rous sarcoma virus pseudotype RSV(HPRS-103) in 12 avian species: support for a new avian retrovirus envelope subgroup, designated J. J. Gen Virol. 73 (Pt 11), 2995-2997. doi: 10.1099/0022-1317-73-11-2995

Presloid, J. B., and Novella, I. S. (2015). RNA viruses and RNAi: quasispecies implications for viral escape. Viruses 7, 3226-3240. doi: 10.3390/v7062768

Qin, A., Lee, L. F., Fadly, A., Hunt, H., and Cui, Z. (2001). Development and characterization of monoclonal antibodies to subgroup J avian leukosis virus. Avian Dis. 45, 938-945.

Scarborough, R. J., and Gatignol, A. (2017). RNA interference therapies for an HIV-1 functional cure. Viruses 10:8. doi: 10.3390/v10010008

Shittu, I., Adedeji, A. J., Luka, P. D., Asala, O. O., Sati, N. M., Nwagbo, I. O., et al. (2019). Avian leukosis virus subgroup - J as a contaminant in live commercially available poultry vaccines distributed in Nigeria. Biologicals 57, 29-33. doi: 10.1016/j.biologicals.2018.11.003

Srikantha, T., Landsman, D., and Bustin, M. (1990). A single copy gene for chicken chromosomal protein HMG-14b has evolutionarily conserved features, has lost one of its introns and codes for a rapidly evolving protein. J. Mol. Biol. 211, 49-61. doi: 10.1016/0022-2836(90)90010-j

Su, Q., Cui, Z., Zhang, Z., Cui, Z., Chang, S., and Zhao, P. (2020). Whole-genome analysis of an emerging recombinant avian leukosis virus in yellow chickens, south China. Transbound. Emerg. Dis. 67, 2254-2258. doi: 10.1111/tbed.13574

Su, Q., Li, Y., Li, W., Cui, S., Tian, S., Cui, Z., et al. (2018b). Molecular characteristics of avian leukosis viruses isolated from indigenous chicken breeds in China. Poult. Sci. 97, 2917-2925. doi: 10.3382/ps/pex367

Su, Q., Li, Y., Cui, Z., Chang, S., and Zhao, P. (2018a). The emerging novel avian leukosis virus with mutations in the pol gene shows competitive replication advantages both in vivo and in vitro. Emerg. Microbes Infect. 7:117. doi: 10.1038/ s41426-018-0111-4

Su, Q., Zhang, Y., Li, Y., Cui, Z., Chang, S., and Zhao, P. (2019). Epidemiological investigation of the novel genotype avian hepatitis $\mathrm{E}$ virus and co-infected 
immunosuppressive viruses in farms with hepatic rupture haemorrhage syndrome, recently emerged in China. Transbound. Emerg. Dis. 66, 776-784. doi: $10.1111 /$ tbed.13082

van Rij, R. P., and Andino, R. (2006). The silent treatment: RNAi as a defense against virus infection in mammals. Trends Biotechnol. 24, 186-193. doi: 10. 1016/j.tibtech.2006.02.006

Wang, H., Feng, Q., Wei, L., Zhuo, L., Chen, H., Diao, Y., et al. (2017). Significant inhibition of Tembusu virus envelope and NS5 gene using an adenovirusmediated short hairpin RNA delivery system. Infect. Genet Evol. 54, 387-396. doi: 10.1016/j.meegid.2017.08.001

Wang, P., Lin, L., Shi, M., Li, H., Gu, Z., Li, M., et al. (2020b). Vertical transmission of ALV from ALV-J positive parents caused severe immunosuppression and significantly reduced marek's disease vaccine efficacy in three-yellow chickens. Vet. Microbiol. 244:108683. doi: 10.1016/j.vetmic.2020.108683

Wang, P., Li, M., Li, H., Lin, L., Shi, M., Gu, Z., et al. (2020a). Full-length cDNA sequence analysis of 85 avian leukosis virus subgroup $\mathrm{J}$ strains isolated from chickens in China during the years 1988-2018: coexistence of 2 extremely different clusters that are highly dependent upon either the host genetic background or the geographic location. Poult. Sci. 99, 3469-3480. doi: 10.1016/ j.psj.2020.04.023

Wang, X., Zhao, P., and Cui, Z. Z. (2012). Identification of a new subgroup of avian leukosis virus isolated from Chinese indigenous chicken breeds. Bing Du Xue Bao 28, 609-614.

Wang, Y., Fang, L., Li, J., Li, Y., Cui, S., Sun, X., et al. (2016). Rescue of avian leukosis subgroup-J-associated acutely transforming viruses carrying different lengths of the v-fps oncogene and analysis of their tumorigenicity. Arch. Virol. 161, 3473-3481. doi: 10.1007/s00705-016-3035-0

Wang, Y., Xu, S., Li, S., Su, H., Chang, S., Li, Y., et al. (2015). Lamivudine inhibits the replication of ALV-J associated acutely transforming virus and its helper virus and tumor growth in vitro and in vivo. Front. Microbiol. 6:1306. doi: 10.3389/fmicb.2015.01306
Wei, R., Ma, X., Wang, G., Guo, H., Liu, J., Fan, L., et al. (2015). Synergistic inhibition of avian leukosis virus subgroup J replication by miRNA-embedded siRNA interference of double-target. Virol. J. 12:45. doi: 10.1186/s12985-0150277-5

Westerhout, E. M., Ooms, M., Vink, M., Das, A. T., and Berkhout, B. (2005). HIV1 can escape from RNA interference by evolving an alternative structure in its RNA genome. Nucleic Acids Res. 33, 796-804. doi: 10.1093/nar/gki220

Zhang, Y., Su, Q., Zhang, Z., Cui, Z., Chang, S., and Zhao, P. (2020). Molecular characteristics of the re-emerged avian leukosis virus in China, 2018-2019. Transbound. Emerg. Dis. 67, 1141-1151. doi: 10.1111/tbed.13440

Zhou, D., Xue, J., Zhang, Y., Wang, G., Feng, Y., Hu, L., et al. (2019). Outbreak of myelocytomatosis caused by mutational avian leukosis virus subgroup J in China, 2018. Transbound. Emerg. Dis. 66, 622-626. doi: 10.1111/tbed.13096

Conflict of Interest: The authors declare that the research was conducted in the absence of any commercial or financial relationships that could be construed as a potential conflict of interest.

Publisher's Note: All claims expressed in this article are solely those of the authors and do not necessarily represent those of their affiliated organizations, or those of the publisher, the editors and the reviewers. Any product that may be evaluated in this article, or claim that may be made by its manufacturer, is not guaranteed or endorsed by the publisher.

Copyright (C) 2022 Wang, Su, Liu, Li, Sun, Liu, Xue, Chang, Wang and Zhao. This is an open-access article distributed under the terms of the Creative Commons Attribution License (CC BY). The use, distribution or reproduction in other forums is permitted, provided the original author(s) and the copyright owner(s) are credited and that the original publication in this journal is cited, in accordance with accepted academic practice. No use, distribution or reproduction is permitted which does not comply with these terms. 